\title{
Attitudes Towards Cousin Marriages: Findings Among Young People from Mexico
}

\author{
Abraham P. Buunk ${ }^{1,2,3} \cdot$ Karlijn Massar ${ }^{4}$ \\ Received: 29 January 2020 / Revised: 17 March 2020 / Accepted: 18 March 2020 / Published online: 1 April 2020 \\ (C) The Author(s) 2020
}

\begin{abstract}
The present research examined how life history and resistance against interethnic mating were related to positive and negative attitudes towards cousin marriages among young people aged between 15 and 25 from a rural area in the Mexican state of Oaxaca. The sample included three ethnic groups: Mestizos (people of mixed Spanish and indigenous descent, $n=84$ ), indigenous Mixtecs $(n=83)$, and Afro-Mexicans $(n=33)$. In general, respondents reported more negative than positive attitudes towards cousin marriage. Among the Mestizos, but not in the other ethnic groups, women reported more negative attitudes than men did. The main objections against marrying a cousin were that it might lead to family conflict and might result in genetic defects of one's offspring. The main positive aspect of cousin marriage that participants mentioned was that one would marry someone with the same values. The ethnic groups did not differ in their attitudes towards cousin marriages. A slower life history was related to a more negative (but not a less positive) attitude towards cousin marriages, whereas resistance against out-group mating was related to a more positive (but not a less negative) attitude towards cousin marriages. The implications of the results are discussed in the context of life history theory, the benefits of in-group marriage, and the potential positive and negative effects of cousin marriages.
\end{abstract}

Keywords Consanguineous marriage $\cdot$ Cousin marriage $\cdot$ Mexico $\cdot$ Life history $\cdot$ Intergroup marriage

\section{Introduction}

There is a considerable cultural and historical variation in attitudes towards cousin marriages (cf. Wilmsen Thornhill and Thornhill 1987), and various theories have been put forward to explain such variation (e.g., Ember 1975). As Buunk and Hoben (2013) noted, until the middle of the nineteenth century, cousin marriage was allowed in the USA and in many European countries. However, during the nineteenth century, attitudes towards cousin marriage in the Western world became gradually more negative, particularly due to the

Abraham P. Buunk

a.p.buunk@rug.nl

1 Department of Psychology, University of Groningen, Grote Kruisstraat 2/1, 9712 TS Groningen, The Netherlands

2 Netherlands Interdisciplinary Demographic Institute, The Hague, The Netherlands

3 Universidad Católica del Uruguay, Montevideo, Uruguay

4 Maastricht University, Maastricht, The Netherlands conviction that the offspring of cousins might suffer from genetic defects (see e.g., Bittles and Neel 1994). At present, many states in the USA have laws that prohibit marriages between cousins or laws that regulate this practice (Ottenheimer 1996), but cousin marriage is legal in all European countries. Nevertheless, this type of union is generally disapproved of (Paul and Spencer 2008), and in Western countries, sexual relationships between cousins tend to evoke moral indignation as well as disgust (Antfolk et al. 2012; Lespiau and Kaminski 2016). Similarly, in many East Asian countries, negative attitudes towards cousin marriage are prominent. For example, in northern India, to guarantee that the bride and groom are not genetically related, the lineages of the potential spouses are examined up to five generations on the female side and seven generations on the male side (Bittles 2002). However, in many Islamic countries in the Middle East the attitudes towards cousin marriage are quite accepting and even positive, and such marriages may constitute up to $50 \%$ of the marriages in countries such as Jordan, Kuwait, Iran, and Saudi Arabia (Hoben et al. 2016; Jaber et al. 1996; see also Korotayev 2000).

There are various lines of evidence that suggest that cousin marriages may be adaptive under certain conditions. First, 
throughout the history of Western civilization, marriages between cousins have often been accepted or even encouraged, especially in the higher social classes, to prevent the division of family property. Second, a low availability of mates, as may occur in isolated communities, may induce individuals to marry intimates (cf. Ember 1975). Indeed, Hoben et al. (2016), using Murdock's Standard Cross Cultural Sample (SCCS), found that a high level of geographic isolation was associated with a higher prevalence of cousin marriages. Third, in this same study, it was found that a high pathogen prevalence predicted the occurrence of cousin marriages independently of geographic isolation. Hoben et al. (2010) argued that consanguineous marriages may arise adaptively to maintain coadapted gene complexes that defend against local pathogens. In an analysis involving 72 countries worldwide, they found indeed a greater prevalence of inbreeding by consanguineous marriage in geographical regions that, historically, have had high levels of disease-causing parasites.

Remarkably, there have been few investigations of the actual attitudes with respect to cousin marriage in modern populations, and there is not much known about the individual difference variables that may explain these attitudes. In a recent study among young people in The Netherlands, it was found that, although overall attitudes towards cousin marriages were rather negative, Moroccan immigrants had considerably less negative (but not more positive) attitudes than both those with a Dutch or Turkish background, who did not differ from each other. The finding that Moroccans had a less negative attitude towards cousin marriage than the Dutch was expected on the basis of the well-documented prevalence of cousin marriages in many Arab countries mentioned above (Buunk 2017).

The present research was conducted among young people from three ethnic groups in the state of Oaxaca in Mexico, in part as a follow-up of a similar study among adults from this region (Buunk and Hoben 2013). In this latter study, it was shown that a fast life history was an important independent determinant of attitudes towards cousin marriages. There were three reasons to conduct the present research. First, young people tend to differ from their parents in what constitutes an appropriate mate for them. Research has shown that parents tend to emphasize features reflecting a partner from the in-group, i.e., someone who has a similar religious, similar social class, similar ethnic background, and not being poor. In contrast, young people themselves tend to emphasize features reflecting a good genetic quality, like attractiveness, health, physical fitness, and creativity (Buunk et al. 2008). Here, we extend this research to attitudes about cousins as possible mates. The second reason for the current study was that selecting a mate is more relevant and salient for young than for adult people, and we therefore included a variable that was not included in the study by Buunk and Hoben (2013), i.e., a resistance against out-group dating.

\section{Life History}

The basic assumption of Life History Theory is that individuals, in order to successfully reproduce, have to make a tradeoff between mating effort, i.e., finding a mate and courting him or her, and parenting effort, i.e., gestation, childbirth, and postnatal care of children (e.g., Chisholm 1993; Figueredo et al. 2006). These trade-offs can be ordered on a scale referred to as the "fast" vs. "slow" continuum of life history strategy. Individuals at the faster end of the continuum tend to start early with sexual relationships, have more offspring without great investment in them, and tend to invest disproportionately in obtaining mating opportunities, whereas individuals at the slower end of the continuum tend to postpone sexual activity, to be more selective in their mate choice, to produce fewer offspring, and to be more involved with their offspring. A fast life history strategy tends to develop in particular in response to stressful experiences in one's childhood environment and family — such as conflicts between one's parents, the absence of an investing father, or traumatic separation from one's parents (Figueredo et al. 2007). In contrast, a slow life history tends to be characteristic of individuals who grow up in predictable circumstances, in harmonious homes, with a father who is present and invests in his children (e.g., Belsky et al. 1991; Ellis 2004; Pesonen et al. 2008; Tither and Ellis 2008).

Individual differences in life history strategy have also been shown to be associated with personality traits and social attitudes. For example, individuals with a slower life history tend to be more agreeable and conscientious and less neurotic and impulsive (Gladden et al. 2009). On the other hand, individuals with a fast life history strategy tend to take more risks (Wang et al. 2009) and tend to view out-group members as more threatening (Figueredo et al. 2011). Because marrying cousins over a number of generations may involve genetic risks and because individuals who develop a slower life history strategy are risk-averse and more selective in their mate choice (e.g., Figueredo and Wolf 2009), we predicted that such individuals would have a more negative attitude towards cousin marriages (see also Buunk and Hoben 2013). This prediction is in line with the finding of Figueredo and Wolf (2009) that individuals with a slow life history practice higher levels of assortative mating than those with a fast life history. Individuals with a fast life history strategy will take more risks and will be less selective in their mate preferences, resulting in less negative or more positive attitudes towards cousin marriage (cf. Ember 1975). 


\section{Resistance Against Out-Group Mating}

Although affected by life history, in most societies, individuals prefer in general to date and marry others from the same religious or ethnic group, and the resistance towards dating and marrying out-group members tends to be quite strong, in particular among older generations (e.g., Apostolou 2014; Dubbs and Buunk 2010; Uskul et al. 2011) and among members of national minority groups (e.g. Germans living in the Netherlands; Klavina and Buunk 2013). Cousin marriages are more prevalent in societies with high levels of negative ethnocentrism (i.e. a dislike of other ethnic groups; Dutton et al. 2016). Cousin marriages may be viewed as a rather extreme form of marriages within the in-group. Both during human evolution and in modern times, in-group members might be called upon to provide help and support during scarcity or betweengroup conflicts. For example, in modern day Iraq, the main building block of society is cousin marriage. Iraq is composed of three main groups and each of these groups is divided into smaller tribes, clans, and extended families, each with their own feuds, rivals, and alliances. Such societal structures, along with "existential insecurity" due to conflicts, causes Iraqi individuals to exhibit high levels of solidarity with their in-group, along with high levels of xenophobia (Inglehart et al. 2006).

In addition, marrying a cousin may facilitate the transition for a woman to her husband's family and may allow a woman to maintain ties with her natal family. Just like, or in fact even more than, marrying others within the same ethnic group, marrying a cousin may keep the possessions of the family together, may maintain the status of the family in society, may facilitate obtaining support and help from other people of the same ethnic group, and may foster the cohesion of the in-group. On the basis of the previous reasoning, we expected that young people who have more resistance against dating out-group members would have a more positive or less negative attitude towards cousin marriage.

\section{Sex Differences}

Lastly, we expected a number of sex differences. First, a number of studies have shown that girls have a higher resistance against intergroup dating than boys (Carol and Teney 2015; McDonald et al. 2015). For example, Huschek et al. (2011) found among men of Turkish and Moroccan descent living in the Netherlands had had more often a non-co-ethnic partner than women o the same descent, suggesting that minority men may have more positive attitudes towards interethnic marriage than minority women have. Second, we expected that girls would be more disapproving of marriage between cousins than boys would be. From an evolutionary perspective, while for men, the minimal investment to produce offspring is low (i.e., one act of sexual intercourse), for women, the investment that is necessary to gestate a child and the amount of postnatal care is very great, making it more costly for a woman to invest in a child that may suffer from harmful recessive mutations (Trivers 1972). Consequently, women may be more sensitive to the potential disadvantages of cousin marriages than men. Indeed, in a study among young people from The Netherlands, women reported more negative attitudes towards cousin marriages than men did (Buunk 2017). We therefore expected similar sex differences in the present study.

\section{The Mexican Context}

The present research was conducted among young people from a rural population in Oaxaca, one of the poorest states of Mexico. For a number or reasons, this state constitutes an important context to study attitudes towards cousin marriage. A study by Little and Malina (2005) in an indigenous Zapotec community in the same region showed in general a low level of consanguinity, even though this community was quite isolated, suggesting that in the state of Oaxaca, cousin marriages may in general be viewed quite negatively. However, Cabeza de Baca and Figueredo (2017) found that Oaxaca ranked 13th among the 32 Mexican states on an index reflecting the prevalence of a variety of parasites. As parasite burden has been found to be an important driver of a fast life history as well as of ethnocentrism (e.g., Fincher and Thornhill 2012; Figueredo et al. 2012), attitudes towards cousin marriage may not be particularly negative in this state. In any case, life history and resistance against out-group mating may be quite salient determinants of attitudes towards cousin marriage in the state of Oaxaca.

As noted above, the current study was a follow-up to a study among adults from the same state described by Buunk and Hoben (2013). Participants were young people aged 15 to 25 . By the age of 15 , most girls have had their first period, boys will have entered puberty, and most children will have become interested in romantic relationships with the opposite sex. In Mexico, the mean age at marriage for women is 22.4 and for men 24.6. Therefore, young people in the age range of our participants will generally be, or recently have been, confronted with potential mates and will have developed attitudes towards dating and marriage.

We examined young people from three distinct ethnic groups and follow here the description by Buunk and Hoben (2013) of these groups. The first group are the Mixtecs, an indigenous people whose number is somewhere between 250,000 and 500,000. They descend from of the people who constituted one of the major civilizations of Middle America. The Mixtec region covers most of the current state of Oaxaca. The Mixtecs are considered to be a very cohesive ethnic group that maintains its identity despite the high level of migration (e.g., see Joyce 2010). Although, historically, indigenous cultures such as the Mixtecs have been considered inferior (e.g., see Stutzman 1981), around 30\% of the Mexican population 
considers themselves as American-Indian. The second ethnic group we included were Mestizos. In total, around $60 \%$ of the Mexican population perceive themselves to be Mestizos. Whether one considers oneself as a Mestizo is to an important extent dependent on political and cultural factors and does not only depend on actual or assumed ancestral origins (e.g., Knight 1990). Following the Mexican revolution, the Mestizos were promoted as the prototypical Mexicans, when a new ideology of mestizaje emerged that defined Mexico as essentially a Mestizonation. Finally, we included a quite different ethnic minority group, i.e., Afro-Mexicans. It has been estimated that around 250,000 Africans were brought as slaves to Mexico (Bennett 2009). In line with anthropologist Laura Lewis (2000), a specialist on this ethnic group, we simply refer to Afro-Mexicans as Blacks, a term generally used in Oaxaca to refer to them without racial pejorative connotations. Because most Blacks were absorbed into the Mestizo population, by the end of the colonial era, Blacks were rarely recognized as a distinct ethnic group (Lewis 2000; Villarreal 2010). However, over the past years, there has been somewhat more attention for the African roots of the Mexican Blacks, and individuals identify themselves either as Black or Mestizo. The state of Oaxaca, where the present research was conducted, has a substantial Black population.

To summarize, in the current research, we expected that a more negative attitude towards cousin marriages would be related to a slow life history strategy and that a more positive attitude would be related to resistance against out-group marriages. In addition, we expected that women would more than men show resistance against outgroup mating, as well as a more negative or less positive attitude towards cousin marriage.

\section{Method}

\section{Selection of Respondents and Data Collection}

The data collection was done in collaboration with the Centro de Investigaciones y Estudios Superiores en Antropología Social (CIESAS) and was executed under the supervision of a research assistant from the region. To collect the data, the research assistant first went to the local officials (comisariado) and explained the nature of the research and of the questionnaire. A letter of recommendation given by the CIESAS helped considerably because it convinced the officials that she was just going to collect data and would not promote any political viewpoint. The officials arranged the day and time at which she could administer the questionnaire. Next, young people in the area were approached and asked if they did fit the criteria and asked if they were willing to fill out the questionnaire. The participants were all paid 65 Mexican pesos (around \$6) for their participation.

The sample consisted of 101 women and 102 men. Most ( $80 \%$ ) were single, and $13 \%$ was married, with few people being divorced, separated, or widowed $(8 \%)$. Similar numbers of the sample were indigenous Mixtecs $(42 \%, n=83)$ and Mestizos $(42 \%, n=84)$, while $17 \%(n=33)$ were Blacks. The sexes were nearly equally distributed over the three ethnic groups. A large majority (89\%) was Roman Catholic. As intended, the ages ranged from 15 to 25 , and the mean age was $M=18.80(S D=3.47)$. The educational level was only primary school (14\%), secondary school $(48 \%)$, preparatory education (24\%), technical education $(2 \%)$, and university $(4 \%)$.

\section{Measures and Procedure}

Attitudes Towards Cousin Marriage To assess these attitudes, the questionnaire used by Buunk (2017) was used. This questionnaire consists of 9 items, 4 of these express a possible negative and 5 of which express a possible positive consequence of marrying a cousin. The questionnaire starts with the stem "Marrying a cousin...." Then the 9 items followed to which participants indicated their agreement on a 5-point scale. The five positive statements included (1) means that you marry someone with the same values; (2) enhances the unity in the family; (3) keeps wealth in the family; (4) makes it easier to get along with your spouse; (5) makes your marriage more stable. The four negative statements included (1) may lead to children having a high risk of defects; (2) is wrong for religious reasons; (3) leads to family conflict; (4) leads to a relationship without passion. A factor analysis with varimax rotation showed two clear, about equally strong factors, with the first factor explaining $29.74 \%$ of the variance, consisting of the five items emphasizing the positive aspects of cousin marriage (all loadings higher than .58, with four loadings higher than .72), and the second factor explaining $23.58 \%$ of the variance, consisting of the four items emphasizing the negative aspects of cousin marriage (all loadings higher than .52 , with three loadings higher than .74). These factors were used to construct a subscale with all the negative items (alpha $=.61$ ), and a subscale with all the positive items (alpha $=$ .76). There was no correlation between both scales, $r=.00$.

Life History Strategy This variable was measured with the Mini-K Life History Strategy Short Form(Figueredo et al. 2006), a 20-item short form of the Arizona Life History Battery (ALHB; Figueredo 2007). The ALHB is a questionnaire containing a series of behavioral and cognitive indicators of life history strategy collected and adapted from various original sources. In a series of psychometric studies, Figueredo and his colleagues (e.g., Figueredo et al. 2006) 
have found a latent higher order construct underlying these indicators, referred to as the "slow" factor. This construct is characterized by a number of reproductive, parental, and sexual behaviors, including good executive functions, positive relationships with one's parents, positive attachment to an adult partner, low mating effort, low Machiavellianism, low levels of risk taking, more foresight and planning, and persistence and self-directedness. The Mini-K correlates 0.85 with the full $A L H B$ (Gladden et al. 2008) and uses a 7-point Likert scale, which ranges from -3 (disagree strongly) to +3 (agree strongly), with higher scores indicating a slower life history strategy. Cronbach's alpha in the present sample was .73, $M=$ $31.29, S D=12.39$.

Resistance to Interethnic Mating This scale consisted of six items developed by Buunk (2017), based in part on the scale for intergroup mating competition developed by Klavina et al. (2009). The items were answered on a five-point scale from 1 (strongly disagree) to 5 (strongly agree). Examples of items are "Men and women from different ethnic groups have too different backgrounds to get married," "People who marry people from another ethnic group are responsible for the deterioration of their community," "When a man receives attention from many women who want to date him, he should give the priority to the women of his own group," and "Marrying someone from another ethnic group may cause problems for the children of this marriage." High scores indicate greater opposition to interethnic mating. In the present sample, the reliability was satisfactory: $\alpha=73, M=28.36, S D=5.33$.

\section{Results}

\section{Attitude Towards Cousin Marriage}

Paired samples $t$ tests indicated that, overall, participants did agree most with the negative statements pertaining to marrying a cousin and least with the positive statements (see Table 1), for negative attitudes $M=3.22, S D=1.09$, for positive attitudes $M=2.40, S D=.1 .00, t(198)=7.94, p<.001$. Correlations revealed that a slower life history strategy was positively associated with more negative attitudes $(r=.28$, $p<.001)$ but not with less positive attitudes towards cousin marriage $(r=.08, p=.34)$. In contrast, higher opposition to interethnic mating was associated with more positive attitudes towards cousin marriage $(r=.31, p<.001)$ but not with less negative attitudes towards cousin marriage $(r=.03, p=.34)$. In addition, unlike what we expected, women and men did not differ in their positive nor negative attitudes towards marrying a cousin, $t \mathrm{~s}(199)<1.29, p \mathrm{~s}>.20$.

In general, as shown in Table 1, participants disagreed on average that marrying a cousin would enhance the unity in the family, would keep wealth in the family, would make it easier to get along with one's spouse, or would make a marriage more stable. However, on average, participants agreed moderately with respect to the statement that marrying a cousin would mean that you would marry someone with the same values. Taking this last item as the reference category, the results showed that for the positive attitudes, this item stood out in the sense that all other positive attitudes differed significantly from this item $(p \mathrm{~s}<.001)$ but not from each other $(p-$ $\mathrm{s}>.09$; Wilks lambda $=.70, F(4,197)=21.58, p<.001)$.

As Table 1 shows, participants did on average more or less to the same extent agree with this latter statement as with the statement that marrying a cousin is wrong for religious
Table 1 Means (SD) and withinscale differences between items for the positive and negative items of the attitudes towards cousin marriage scales

\begin{tabular}{|c|c|c|c|}
\hline "Marrying a cousin..." & M & $\mathrm{SD}$ & $95 \% \mathrm{CI}$ \\
\hline \multicolumn{4}{|l|}{ Positive attitudes } \\
\hline ...means that you marry someone with the same values & 3.14 & 1.54 & - \\
\hline ...enhances the unity in the family & 2.12 & 1.38 & {$[.77,1.26]^{* *}$} \\
\hline ...keeps wealth in the family & 2.28 & 1.35 & {$[.64,1.07]^{* *}$} \\
\hline ...makes it easier to get along with your spouse & 2.28 & 1.36 & {$[.62,1.10]^{* *}$} \\
\hline ...makes your marriage more stable & 2.12 & 1.34 & {$[.77,1.24]^{* *}$} \\
\hline \multicolumn{4}{|l|}{ Negative attitudes } \\
\hline ...leads to family conflict ${ }^{\#}$ & 3.79 & 1.55 & - \\
\hline ...may lead to children having a high risk of defects & 3.17 & 1.65 & {$[.40, .83]^{* *}$} \\
\hline ...is wrong for religious reasons & 3.22 & 1.53 & {$[.36, .81]^{* *}$} \\
\hline ...leads to a relationship without passion & 2.76 & 1.36 & {$[.79,1.28]^{* *}$} \\
\hline
\end{tabular}

Comparisons between items were made within the subscales. 95\% CI is given for the difference with the comparison reference item

${ }^{\#}$ Comparison reference item; significance of difference $* * p<.001, * p<.01$ 
reasons and would result in children with a higher risk of mental and physical defects. Of all negative statements, people showed the most agreement with the statement that cousin marriage might lead to family conflict and the least with the statement that marrying a cousin would lead to a relationship without passion. For the negative attitudes, all items significantly differed from the most negative item that we used as the reference item ("Marrying a cousin leads to family conflict"; $p \mathrm{~s}<.001)$ and from each other; Wilks lambda $=.71, F$ $(3,198)=27.31, p<.001$. Only two items did not statistically differ from one another: "Marrying a cousin is wrong for religious reasons" and "Marrying a cousin may lead to children having a high risk of genetic defects" $(p=.78)$.

We also examined if the study variables did correlate with educational level and income. Only a negative attitude towards cousin marriage correlated negatively with educational level $(r=-.17, p<.05)$ and income $(r=-.17, p<.05)$, the other $r \mathrm{~s}<.12, p \mathrm{~s}>.10$. Thus, individuals with a higher educational level and higher income had a less negative attitude towards cousin marriage.

\section{Effect of Life History Strategy, Gender, and Ethnic Group}

To examine the first central issue in this research, i.e., how life history strategy was related to the attitude towards marrying a cousin among the young people in the three ethnic groups, we examined the effects on positive and negative attitudes towards cousin marriage by conducting two GLM analyses with gender and ethnic group as factors and life history strategy as a continuous variable. All main effects and interactions were included in the model.

Negative Attitudes Towards Cousin Marriage There was a strong significant main effect of life history strategy on negative attitudes towards cousin marriages $(F(1,193)=$ $15.88, p<.001)$ and an interaction between gender and ethnic group $(F(2,193)=3.09, p<.05)$. Closer inspection of this interaction revealed that only among the Mestizos, women $(M=3.56, S D=1.03)$ had a more negative attitude towards cousin marriages than men $(M=2.86, S D=.80), t(198)=7.94, p<.001$. In both other ethnic groups, the sex difference was not significant, $t \mathrm{~s}<.60, p \mathrm{~s}>.55$. No other main effects or interactions were significant $\left(F_{\mathrm{S}}<2.41, p \mathrm{~s}>.09\right)$.

Positive Attitudes Towards Cousin Marriage There was a main effect of ethnic group, $F(1,193)=3.30, p=.05$, which indicated that Blacks had more positive attitudes towards cousin marriage than Mestizos $(p=.02)$ and Mixtecs $(p=.08)$. None of the other main or interaction effects were significant, $F \mathrm{~s}<2.21, p \mathrm{~s}>.11$.

\section{Effect of Resistance Against Interethnic Mating, Gender, and Ethnic Group}

Next, the effects on positive and negative attitudes towards cousin marriage of gender, ethnic group, and resistance to interethnic mating were investigated by conducting GLM analyses. All main effects and interactions were included in the model.

Negative Attitudes towards Cousin Marriage The analyses revealed that none of the effects was significant, $F_{\mathrm{s}}<1.70$, $p \mathrm{~s}>.18$.

Positive Attitudes towards Cousin Marriage The analysis revealed a significant main effect of resistance to interethnic mating on positive attitudes towards cousin marriages ( $F$ $(1,184)=19.23, p<.001)$ but with the exception of a marginally significant interaction between gender and ethnic group, $F(2,184)=2.60, p=.08$, none of the other effects was significant $(F s<1.89, p$ 's $>.15)$. Thus, across the three ethnic groups, and independent of gender, people who had a strong resistance against out-group dating had more positive attitudes towards cousin marriage.

\section{Discussion}

The present research among young people belonging to three ethnic groups in the state of Oaxaca in Mexico showed that, as in the study among adults from this region (Buunk and Hoben 2013), participants had overall a more negative than positive attitude to marrying a cousin, and the three ethnic groups did not differ in this respect. In line with what is usually assumed (e.g., Ember 1975; Ottenheimer 1996), an important objection against marrying a cousin was the risk of genetic defects of children born in such marriages. However, this was considered less important than the belief that such marriages might induce family conflict, although more important than the belief that it was wrong for religious reasons. Cousin marriage was not considered to enhance the unity in the family, to keep wealth in the family, or to make it easier to get along with your spouse. Remarkably, on average, the participants felt that one of the advantages of cousin marriage was that one would marry someone with the same values, which was viewed as a more positive consequence of cousin marriage than any other statement.

Overall, the young people in this Mexican sample tended to have somewhat less negative attitudes towards cousin marriage than the Mexican adults from the same region (Buunk and Hoben 2013), but their responses were similar to those of young Dutch people from various ethnic groups, except that in the present sample, religious reasons were a more important objection and marrying someone with the same values a more relevant consideration (Buunk 2017). Overall however, the present 
findings suggest that attitudes towards cousin marriages in such diverse countries as Mexico and The Netherlands-where the law does not prohibit cousin marriage - do not differ in major ways. This is particularly noteworthy as Oaxaca is one of the poorest states of Mexico, with a rather high prevalence of parasites, which might foster a more positive or less negative attitude towards cousin marriage (cf. Cabeza de Baca and Figueredo 2017; Hoben et al. 2010). The findings in the present study seem to underline that the attitudes towards cousin marriages in Western cultures, including Mexico, differ from those in Middle Eastern countries such as Iran, where cousin marriage is prevalent (e.g. Akrami and Osati 2007).

Unlike what we predicted and unlike what was found among adult Mexicans (Buunk and Hoben 2013), we found no overall sex difference in the attitudes towards cousin marriage. However, in the Mestizo group - which is numerically and culturally the dominant group in Mexico-women had a more negative attitude towards cousin marriage than men. Although the same sex difference was not found in the two minority ethnic groups, this sex difference is in line with parental investment theory (Trivers 1972). Females, compared with males, bear the largest physiological burden with respect to reproduction (conception, birth, and postnatal care) and are restricted in terms of the amount of offspring they can produce within a lifetime, investing in a potentially unviable offspring would be very costly. Therefore, women may be more averse to the idea of marrying a cousin if they believe this may cause them to have children with physical or mental deficits.

The present research also indicated that participants did not consider negative aspects of cousin marriage to be the inverse of positive aspects of cousin marriage: There was no association between these two concepts, suggesting that positive and negative attitudes towards marrying one's cousin are not merely two opposites of a continuum but distinct constructs. Moreover, the fact that the participants had significantly more negative attitudes than positive attitudes towards cousin marriage is in line with the often found pattern that "bad is stronger than good"-i.e. negative events, emotions, or attitudes outweigh their positive counterparts (Baumeister et al. 2001). Furthermore, positive and negative attitudes were in different ways related to the major predictors: A slow life history was positively associated with a negative attitude but not negatively with a positive attitude towards cousin marriage. This suggests, to put it somewhat extremely, that people with a slow life history, who are characterized by, among others, positive relationships with their parents, a low mating effort, and low levels of risk taking, as well as high levels of foresight and persistence, are just abhorred by the idea of marrying a cousin. Individuals with this type of strategy seem to value "quality over quantity" and as a result are more aversive to the risk of having offspring with genetic defects as a result of mating with kin. This result fits in with theorizing on life history strategies, where a slow life history strategy maximizes long-term reproductive success (e.g., Figueredo et al. 2006; Kaplan and
Gangestad 2005) by having fewer high quality offspring rather than having numerous but lower quality offspring.

While a slow life history strategy was associated with a more negative attitude but not a less positive attitude towards cousin marriage, resistance against out-group mating was associated with a less positive attitude towards cousin marriage but not with a more negative attitude. This was in line with our predictions and suggests indeed, to put it sharply, that people who resist mating with out-group members might rather marry a cousin than an out-group member, presumably because cousins are members of one's in-group. As we argued in the introduction, cousin marriages may be viewed as an explicit and effective way of ensuring the spouse comes from the same group. In present times, attitudes towards cousin marriage tend to be particularly positive in many Islamic countries in the Middle East, where marrying a cousin is viewed as something that might strengthen and maintain the cohesiveness of the clan (Holy 1989). In addition, from the perspective of inclusive fitness, marrying a cousin may also facilitate the transition of a woman to her husband's family as the woman may receive more support from the family of her husband because she is genetically related.

As far as we know, this is probably the first study providing evidence that among young people in Latin America, life history strategy as well as a resistance against out-group mating is quite strongly related to attitudes towards cousin marriage. Our findings clearly indicate that in this young population, negative attitudes towards cousin marriages do reflect primarily a slow life history strategy and positive attitudes towards cousin marriage do reflect an openness to date and mate outside one's ingroup. The present findings are in line with the assumption that a fast life history theory may lead individuals to invest disproportionately in mating as opposed to parenting. This may make one less selective in the choice of a mate (see also Figueredo and Wolf 2009), and less concerned about the possible negative effects on fitness that mating with a cousin might have.

This study has a number of potential limitations. First, except for life history strategy and resistance against out-group mating, we did not explore other factors that might affect the attitude towards cousin marriage, including disease avoidance, social isolation, and scarcity of potential mates ${ }^{1}$. It may be noted, however, that the state of Oaxaca, where the present research was conducted, has a much higher level of parasite prevalence than a country like the Netherlands (cf. Cabeza de Baca and Figueredo 2017), whereas the attitudes towards cousin marriage were the same in both populations. Second, we do not know which aspect of life history strategy is responsible for the effect on the negative attitude towards marrying a cousin. For instance, it may be a result of the fact

We did explore whether, as was found among adults from the same population (Buunk and Hoben 2013), a preference for parental control of mate choice was related to the attitudes towards cousin marriages. That proved not to be the case. 
that those with a slow life history strategy are in general choosier (Figueredo and Wolf 2009) or are in general more cautious than those with a fast life history strategy are. Third, the reliability of the negative attitude measure was low in this sample, which is in part due to the limited number of items. Nevertheless, the fact that we did find such rather consistent and strong effects, which were in line with the theoretical predictions as well, may suggest that the scale is a rather valid measure. Fourth, we had uneven numbers of participants in the three groups, and Blacks were underrepresented, which will have reduced the power to find effects. Finally, it is not certain that the samples were completely representative for the populations studied as, for example, a number of people refused to participate, and it was not possible to draw a completely random sample from each group. Future research may also investigate the influence of childhood environment and current sociodemographic characteristics to determine whether these influence the attitudes towards cousin marriages, as well as the proposed underlying constructs such as life history strategy and attitudes towards intergroup mating.

To conclude then, we collected data from young people in a rural region with different ethnic groups that live in close contact with each other. In addition to an indigenous people, i.e., the Mixtecs, also Mestizos - who constitute the majority of Mexican inhabitants - as well as the rarely studied Black Mexican people were included. By examining how individual differences may affect the factors affecting attitudes towards cousin marriage in various ethnic groups, our research underlines that for a more complete understanding of human mating, future research must attend to the role of life history and resistance against out-group mating in affecting attitudes and behaviors concerning cousin marriages.

Acknowledgments Special thanks to Alejandra Cruz from the CIESAS and her collaborators for the conscientious fieldwork.

Funding Information This work was supported by a grant from the Royal Netherlands Academy of Arts and Sciences to Abraham Buunk.

\section{Compliance with Ethical Standards}

Conflict of Interest The authors declare that they have no conflict of interest.

Open Access This article is licensed under a Creative Commons Attribution 4.0 International License, which permits use, sharing, adaptation, distribution and reproduction in any medium or format, as long as you give appropriate credit to the original author(s) and the source, provide a link to the Creative Commons licence, and indicate if changes were made. The images or other third party material in this article are included in the article's Creative Commons licence, unless indicated otherwise in a credit line to the material. If material is not included in the article's Creative Commons licence and your intended use is not permitted by statutory regulation or exceeds the permitted use, you will need to obtain permission directly from the copyright holder. To view a copy of this licence, visit http://creativecommons.org/licenses/by/4.0/.

\section{References}

Akrami, S. M., \& Osati, Z. (2007). Is consanguineous marriage religiously encouraged? Islamic and Iranian considerations. Journal of Biosocial Science, 39, 313-316. https://doi.org/10.1017/ S0021932006001684.

Antfolk, J., Lieberman, D., \& Santtila, P. (2012). Fitness costs predict inbreeding aversion irrespective of self-involvement: support for hypotheses derived from evolutionary theory. PLoS One, 7, e50613. https://doi.org/10.1371/journal.pone.0050613.

Apostolou, M. (2014). Sexual selection under parental choice: the evolution of human mating behavior. New York: Psychology Press.

Baumeister, R. F., Bratslavsky, E., Finkenauer, C., \& Vohs, K. D. (2001). Bad is stronger than good. Review of General Psychology, 5, 323370. https://doi.org/10.1037/1089-2680.5.4.323.

Belsky, J., Steinberg, L., \& Draper, P. (1991). Childhood experience, interpersonal development, and reproductive strategy: an evolutionary theory of socialization. Child Development, 62, 647-670. https:// doi.org/10.1111/j.1467-8624.1991.tb01558.x.

Bennett, H. L. (2009). Colonial blackness: a history of Afro-Mexico. Bloomington: Indiana University Press.

Bittles, A. H. (2002). The impact of consanguinity on the Indian population. Indian Journal of Human Genetics, 8, 45-45.

Bittles, A. H., \& Neel, J. V. (1994). The cost of human inbreeding and their implications for variation at the DNA level. Nature Genetics, 27, 111-130.

Buunk, A. P. (2017). All in the family: attitudes towards cousin marriages among young Muslims and native Dutch. Evolution, Mind and Behavior, 15, 1-15. https://doi.org/10.1556/2050.2017.0001.

Buunk, A. P., \& Hoben, A. D. (2013). A slow life history is related to a negative attitude towards cousin marriages: a study in three ethnic groups in Mexico. Evolutionary Psychology, 11, 442-458. https:// doi.org/10.1177/147470491301100215.

Buunk, A. P., Park, J. H., \& Dubbs, S. L. (2008). Parent-offspring conflict in mate preferences. Review of General Psychology, 21, 47-62. https://doi.org/10.1037/1089-2680.12.1.47.

Cabeza de Baca, T., \& Figueredo, A.J. (2017). Population-level life history in Italy, Spain and Mexico: the impact of regional climate, parasite burden, and population density. In Figueredo, A.J., Fernandes, H.B.F., \& Cabeza de Baca, T., (Eds), Part 1: the evolutionary dynamics of social biogeography. Mankind Quarterly, 57(3), 326-337.

Carol, S., \& Teney, C. (2015). Attitudes towards intergroup dating among Brussels adolescents: the interaction of gender and ethnicity and its determinants. European Societies, 17, 132-157. https://doi.org/10. 1080/14616696.2014.977322.

Chisholm, J. S. (1993). Death, hope, and sex: life-history theory and the development of reproductive strategies. Current Anthropology, 34, 1-24. https://doi.org/10.1086/204131.

Dubbs, S. L., \& Buunk, A. P. (2010). Parents just don't understand: parentoffspring conflict over mate choice. Evolutionary Psychology, 8, 586598. https://doi.org/10.1177/147470491000800405.

Dutton, E., Madison, G., \& Lynn, R. (2016). Demographic, economic, and genetic factors related to national differences in ethnocentric attitudes. Personality and Individual Differences, 101, 137-143. https://doi.org/10.1016/j.paid.2016.05.049.

Ellis, B. J. (2004). Timing of pubertal maturation in girls: an integrated life history approach. Psychological Bulletin, 130, 920-958. https:// doi.org/10.1037/0033-2909.130.6.920.

Ember, M. (1975). On the origin and extension of the incest taboo. Behavior Science Research, 10, 249-281. https://doi.org/10.1177/ 106939717501000402.

Figueredo, A. J. (2007). A cross-cultural study of assortative pairing for sensational interests, mate value, life history, and delinquency. Abstract. Revista Mexicana de Psicología, Número Especial: XV Congreso Mexicano de Psicología, 6. 
Figueredo, A. J., \& Wolf, P. S. A. (2009). Assortative pairing and life history strategy: a crosscultural study. Human Nature, 20, 317-330. https://doi.org/10.1007/s12110-009-9068-2.

Figueredo, A. J., Vásquez, G., Brumbach, B. H., Schneider, S. M. R., Sefcek, J. A., Tal, I. R., Hill, D., Wenner, C. J., \& Jacobs, W. J. (2006). Consilience and life history theory: from genes to brain to reproductive strategy. Developmental Review, 26, 243-275. https:// doi.org/10.1016/j.dr.2006.02.002.

Figueredo, A. J., Vásquez, G., Brumbach, B. H., \& Schneider, S. M. R. (2007). The K-factor, covitality, and personality: a psychometric test of life history theory. Human Nature, 18, 47-73. https://doi.org/10. 1007/BF02820846.

Figueredo, A. J., Andrzejczak, D. J., Jones, D. N., Smith-Castro, V., \& Montero, E. (2011). Reproductive strategy and ethnic conflict: slow life history as a protective factor against negative ethnocentrism in two contemporary societies. Journal of Social, Evolutionary, and Cultural Psychology, 5, 14-31. https://doi.org/10.1037/h0099277.

Figueredo, A. J., Gladden, P. R., \& Black, C. J. (2012). Parasite stress, ethnocentrism, and life history strategy: Comment on Fincher \& Thornhill. Behavioral and Brain Sciences, 35(2), 87-88. https:// doi-org.proxy-ub.rug.n1/10.1017/S0140525X11000999.

Fincher, C. L., \& Thornhill, R. (2012). Parasite-stress promotes in-group assortative sociality: the cases of strong family ties and heightened religiosity. Behavioral and Brain Sciences, 35, 61-119. https://doi. org/10.1017/S0140525X11000021.

Gladden, P. R., Sisco, M., \& Figueredo, A. J. (2008). Sexual coercion and life history strategy. Evolution and Human Behavior, 29, 319-326. https://doi.org/10.1016/j.evolhumbehav.2008.03.003.

Gladden, P. R., Figueredo, A. J., \& Jacobs, W. J. (2009). Life history strategy, psychopathic attitudes, personality, and general intelligence. Personality and Individual Differences, 46, 270-275. https://doi.org/10.1016/j.paid.2008.10.010.

Hoben, A. D., Buunk, A. P., Fincher, C. L., Thornhill, R., \& Schaller, M. (2010). On the adaptive origins and maladaptive consequences of human inbreeding: Parasite prevalence, immune function and consanguineous marriage. Evolutionary Psychology, 8, 658-676. https://doi.org/10.1177/147470491000800408.

Hoben, A. D., Buunk, A. P., \& Fisher, M. L. (2016). Factors influencing the allowance of consanguineous marriages in the standard cross cultural sample. Evolutionary Behavioral Sciences, 10, 98-108. https://doi.org/10.1037/ebs0000034.

Holy, L. (1989). Kinship, honour and solidarity: cousin marriage in the Middle East. Manchester: Manchester University Press.

Huschek, D., De Valk, H. A. G., \& Liefbroer, A. C. (2011). Does social embeddedness influence union formation choices among the Turkish and Moroccan second generation in the Netherlands? Journal of Comparative Family Studies, 42, 787-808. https://doi. org/10.3138/jcfs.42.6.787.

Inglehart, R., Moaddel, M., \& Tessler, M. (2006). Xenophobia and ingroup solidarity in Iraq: a natural experiment on the impact of insecurity. Perspectives on Politics, 4, 495-505. https://doi.org/10.1017/ S1537592706060324.

Jaber, L., Shohot, M., \& Halpern, G. J. (1996). Demographic characteristics of the Israeli Arab community in connection with consanguinity. Israel Journal of Medical Science, 32, 1286-1289.

Joyce, A. A. (2010). Mixtecs, Zapotecs and Chatinos: ancient peoples of southern Mexico. Malden: Wiley Blackwell.

Kaplan, H. S., \& Gangestad, S. W. (2005). Life history theory and evolutionary psychology. In D. M. Buss (Ed.), Handbook of evolutionary psychology (pp. 68-95). New York: Wiley.

Klavina, L., \& Buunk, A. P. (2013). Intergroup intrasexual competition: reactions towards outgroup members as romantic rivals. Journal of Evolutionary Psychology, 11(3), 93-120. https://doi.org/10.1556/ JEP.11.2013.3.1.
Klavina, L., Buunk, A. P., \& Park, J. H. (2009). Intergroup jealousy: effects of perceived group characteristics and intrasexual competition between groups. In H. Høgh-Oleson, J. Tønnesvang, \& P. Bertelsen (Eds.), Human characteristics: evolutionary perspectives on human mind and kind (pp. 382-397). Cambridge: Cambridge University Scholars.

Knight, A. (1990). Racism, revolution and indigenismo: Mexico, 19101940. In R. Graham (Ed.), The idea of race in Latin America (pp. 71-113). Austin: University of Texas Press.

Korotayev, A. (2000). Parallel-cousin(FBD) marriage, Islamization, and Arabization. Ethnology, 395-407. https://doi.org/10.2307/3774053.

Lespiau, F., \& Kaminski, G. (2016). Fitness costs predict emotional, moral, and attitudinal inbreeding aversion. Frontiers in Psychology, 7, 1860. https://doi.org/10.3389/fpsyg.2016.01860.

Lewis, L. A. (2000). Blacks, Black Indians, Afromexicans: the dynamics of race, nation and identity in a Mexican Moreno community (Guerrero). American Ethnologist, 27, 898-926. https://doi.org/10. 1525/ae.2000.27.4.898.

Little, B. B., \& Malina, R. M. (2005). Inbreeding avoidance in an isolated indigenous Zapotec community in the valley of Oaxaca, southern Mexico. Human Biology, 77, 305-316.

McDonald, M. M., Donnellan, M. B., Cesario, J., \& Navarrete, C. D. (2015). Mate choice preferences in an intergroup context: evidence for a sexual coercion threat-management system among women. Evolution and Human Behavior, 36, 438-445. https://doi.org/10. 1016/j.evolhumbehav.2015.04.002.

Ottenheimer, M. (1996). Forbidden relatives: the American myth of cousin marriage. Champaign: University of Illinois Press.

Paul, D. B., \& Spencer, H. G. (2008). "It's OK, We're not cousins by blood": the cousin marriage controversy in historical perspective. PLoS Biology, 6, 2627-2630. https://doi.org/10.1371/journal.pbio.0060320.

Pesonen, A. K., Räikkönen, K., Heinone, K., Kajantie, E., Forsén, T., \& Erikkson, J. G. (2008). Reproductive traits following a parent-child separation trauma during childhood: a natural experiment during World War II. American Journal of Human Biology, 20, 345-351. https://doi.org/10.1002/ajhb.20735.

Stutzman, R. (1981). El Mestizaje: an all-inclusive ideology of exclusion. In N. Whitten (Ed.), Cultural transformation and ethnicity in modern Ecuador. Chicago: University of Illinois Press.

Tither, J. M., \& Ellis, B. J. (2008). Impact of fathers on daughters' age at menarche: a genetically and environmentally controlled sibling study. Developmental Psychology, 44, 1409-1420. https://doi.org/ 10.1037/a0013065.

Trivers, R. L. (1972). Parental investment and sexual selection. In B. Campbell (Ed.), Sexual selection and the descent of man, 18711971 (pp. 136-179). Chicago: Aldine.

Uskul, A. K., Lalonde, R. N., \& Konanur, S. (2011). The role of culture in intergenerational value discrepancies regarding intergroup dating. Journal of Cross-Cultural Psychology, 42, 1165-1178. https://doi. org/10.1177/0022022110383311.

Villarreal, A. (2010). Stratification by skin color in contemporary Mexico. American Sociological Review, 75, 652-679. https://doi. org/10.1177/0003122410378232.

Wang, X. T., Kruger, D. J., \& Wilke, A. (2009). Life history variables and risk-taking propensity. Evolution and Human Behavior, 30, 77-84. https://doi.org/10.1016/j.evolhumbehav.2008.09.006.

Wilmsen Thornhill, N., \& Thornhill, R. (1987). Evolutionary theory and rules of mating and marriage pertaining to relatives. In C. Crawford, M. Smith, \& D. Krebs (Eds.), Sociobiology and psychology. Ideas, issues, and applications (pp. 373-400). Hillsdale: Erlbaum.

Publisher's Note Springer Nature remains neutral with regard to jurisdictional claims in published maps and institutional affiliations. 